over ro ft. (from 2 to over $3 \mathrm{~m}$.) in thickness, and it and the surface of the glacier beneath it sloped down-glacier at about 14 degrees. The block rested on three plinths of ice, two of which, well underneath the lower thicker end of the boulder, carried most, indeed, in the final stage seen, all the weight of the boulder. The third plinth (Fig. 3, p. 32) which supported the higher end of the block was $18 \frac{1}{2} \mathrm{ft}$. $\left(6 \mathrm{~m}\right.$.) long, of which, when first observed on 6 August, only the lower $4 \frac{1}{2} \mathrm{ft}$. $\left(\mathrm{I} \cdot 5 \mathrm{~m}\right.$.) were carrying the end of the block. The plinth stood about $4 \frac{1}{2} \mathrm{ft} .(\mathrm{I} \cdot 5 \mathrm{~m}$.) above the general level of the glacier surface, and was $5 \mathrm{ft}$. $(\mathrm{r} \cdot 6 \mathrm{~m}$.) wide at the top beneath the block. At the base of the plinth the blue bands were unmodified and dipped up-glacier at 60 degrees, but about $2 \mathrm{ft}$. $(0.6 \mathrm{~m}$.) below the bottom of the block, began smoothly to bend over so as finally to become nearly parallel to the base of the block (Fig. 4, p. 32). Immediately behind the boulder, the top of the plinth had been shaped into shallow longitudinal grooves and was torn across by fissures running at right angles to the direction of movement of the boulder. They were presumably due to the tension arising from the drag of the boulder and indicated how the ice had become rigid once more when released from the pressure of the block.

Owing to the irregularity of the shape of the boulder and its supports, it would be extremely difficult to make a reliable estimate of the pressure on the plinth which had caused the bending of the blue bands. Indeed this pressure must have been gradually lessening for shortly before the end of the expedition, the end of the boulder lost contact with the plinth, the whole weight having been transferred to the other supports.

\title{
ON THE SLIDING OF GLACIERS
}

\author{
By J. Weertman \\ (Naval Research Laboratory, Washington, D.C.)
}

\begin{abstract}
A model is proposed to explain the sliding of any glacier whose bottom surface is at the pressure melting point. Two mechanisms are considered. One is pressure melting and the other is creep rate enhancement through stress concentrations. Neither of the mechanisms operating alone is sufficient to explain sliding. If both mechanisms operate together appreciable sliding can occur.

RÉsumé. On propose un modèle pour expliquer le glissement d'un glacier dont le fond se maintient au point de fusion. On considère deux mécanismes : le fusion de pression et l'augmentation de la vitesse de déformation causée par les concentrations de tension. Ni l'un ni l'autre en agissant seul ne suffit à expliquer le glissement. Mais ensemble ils occasionneraient un glissement assez important.
\end{abstract}

\section{INTRODUCTION}

Nye 1,2,3 has developed a very successful theory of the plastic flow of ice within a glacier. The later version ${ }^{2,3}$ of his theory is based on the creep law of ice which was discovered by Glen ${ }^{4}$. This law is for a temperature close to the melting point,

$$
\text { creep rate }=K=B \sigma^{n}
$$

where $\sigma$ is the stress and $B$ and $n$ are constants. (The creep behavior of metals is quite similar to that of ice. For this reason the extensive work on the creep of metals is of interest to glaciologists and the work on glaciers is interesting to metallurgists.)

Among the results of Nye's theory is a prediction of that portion of the surface velocity of a glacier which is due to creep within the bulk of a glacier. Nye notes that the total surface velocity is the sum of the velocity due to creep within a glacier plus that due to sliding of a glacier over its bed. The velocity due to sliding can make an appreciable contribution to the total surface velocity. 
For example, in the Jungfraufirn borehole experiment ${ }^{5}$ the sliding contributes about one half of the total. McCall ${ }^{6}$ estimates that in Vesl-Skautbreen the sliding accounts for about 90 per cent of the total surface movement. Ward ${ }^{7}$ finds that in the Highway Glacier about 80 per cent of the surface movement is due to sliding.

Nye's theory gives a good estimate of that portion of the surface velocity due to creep within the glacier. There appears to be no theory which can give an estimate of the velocity of sliding of a glacier over its bed. In this paper we wish to develop a model which permits one to make an estimate of this sliding velocity.

\section{TheORY}

The bed of a glacier is an irregular surface which contains many protuberances, etc. At first sight it is surprising that there should be any sliding at all over such a surface. What are the mechanisms that may be invoked to explain it? We believe that there are only two likely mechanisms. One is the old pressure melting phenomenon. With this mechanism if pressure is built up on one side of a protuberance the melting point of ice on this side is lowered. Temperature gradients can be set up and heat will flow. If the bottom of the glacier is at the melting point, ice is melted on the high pressure side of a protuberance; the melted ice flows to the low pressure side where it refreezes. The glacier can thus slide. The main difficulty with using this mechanism by itself is that the sliding would be controlled by the rate of heat flow through the larger protuberances in the glacier bed. Protuberances of the order of magnitude of $100 \mathrm{~cm}$. would limit the sliding to negligible amounts.

A second mechanism which may be invoked to explain glacier sliding is the enhancement of the average creep rate of the ice in the vicinity of the glacier bed through stress concentrations. With this mechanism the creep flow around the smallest obstacles would determine the sliding velocity. If only this mechanism is operative the rate of sliding (as we shall see) is again negligible.

If both these mechanisms operate at the same time it is possible to obtain appreciable sliding in a glacier. (If we are correct there should be no sliding in a glacier whose bottom surface is appreciably below the pressure melting point.) To see this we make the following calculations.

\section{Pressure Melting}

Let us estimate the effect of pressure melting. Consider the idealized glacier bed given in Fig. I (p. 35). In the bed are cubic protuberances of dimensions $L$ which are separated by a distance $L^{\prime}$. We assume that a perfectly smooth rock-ice interface can support only a normal stress and not a tangential one. Then if $\tau$ is the average shear stress which a glacier bed must support, the average normal stress on one side of a protuberance would be of the order of $\tau L^{\prime 2} / L^{2}$ if the hydrostatic pressure were zero. Since the hydrostatic pressure at a glacier bottom is much larger than $\tau$, the probable situation is that the normal stress on the high pressure side of an obstacle is increased by a factor $\frac{1}{2} \tau L^{\prime 2} / L^{2}$ and on the low pressure side is depressed by the same factor. The hydrostatic pressure, $\frac{1}{3}\left(\sigma_{x x}+\sigma_{y y}+\sigma_{z z}\right)$ where $\sigma_{i i}$ is a stress component, is thus increased on the high pressure side by an amount of the order $\frac{1}{3} \times \frac{1}{2} \tau L^{\prime 2} / L^{2}$ and is decreased on the low pressure side by a like amount. The difference in the melting point of ice on the two sides of a protuberance is equal to ${ }^{8} \Delta T$ where $\Delta T=\frac{1}{3} C \tau L^{\prime 2} / L^{2}$. The term $C$ is a constant and is equal to $7 \cdot 4 \times 10^{-9}{ }^{\circ} \mathrm{C}$. dynes $\mathrm{cm} .^{-2}$. The shear stress may also effect the melting point. At the stress level existing at glacier bottoms, the effect should be a second-order one 4 . If the bottom of a glacier is at the melting point, heat will flow from the low pressure side of any protuberance to the high pressure side where it melts the ice. The water formed then flows to the low pressure side where it refreezes and gives up its latent heat. The energy required to keep the cycle going is supplied through the shear stress acting at the bottom of a glacier. 
The total energy which is dissipated into heat at the glacier bottom per unit time and unit area is $S \tau$ where $S$ is the speed of sliding. This amount of energy would melt $S \tau / J H \rho$ volume of ice. Here $H$ is the heat fusion, $J$ is a conversion factor for changing heat units into energy units, and $\rho$ is the density of ice. For a glacier which slides at the rate of 40 meters per year, a typical value, enough heat is dissipated at the bottom to melt one $\mathrm{cm} .^{3}$ of water per year per $\mathrm{cm} .^{2}$ of surface area if $\tau$ is equal to $10^{6}$ dynes $/ \mathrm{cm} .{ }^{2}$. This amount of water is about the same as would be melted from the geothermal heat flow ${ }^{9}$. This volume is much larger than that produced by heat conduction from the top to the bottom of a temperate glacier. If such a glacier is of thickness $d$ then the temperature difference from the top to the bottom is of the order $C d \rho g$ where $g$ is the gravitational constant. The amount of heat conducted per unit time and unit area is equal to $C d \rho g D / d$ where $D$ is the coefficient of conductivity. The volume of ice melted per unit area is equal to $C g D / H$ and is approximately $\mathrm{IO}^{-2} \mathrm{~cm} .{ }^{3}$ per $\mathrm{cm} .{ }^{2}$ per year. The total volume of water which is produced must run off, of course, if there is not to be a net accumulation of water from year to year.

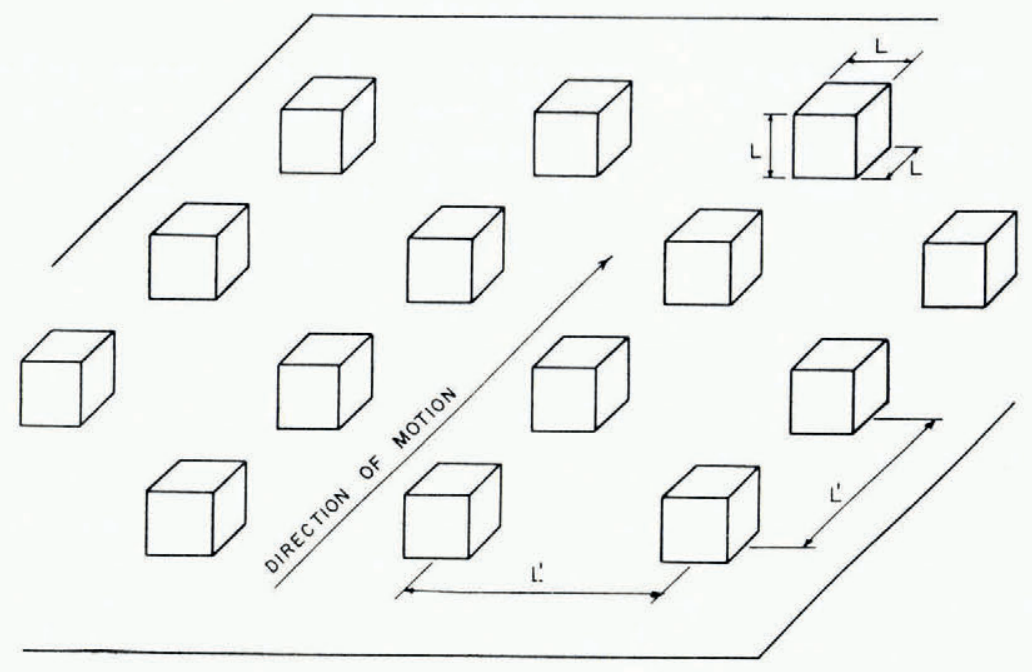

Fig. I. Idealized glacier bed

Because a net amount of heat is produced at a glacier bottom it is possible to have the top surface of a glacier at a temperature appreciably below the melting temperature corresponding to the pressure at the bottom and yet have the bottom surface at the melting point. The condition for this to happen is that the heat produced at the bottom surface be equal to or larger than the heat escaping from the bottom to the top. If $T_{t}$ is the temperature at the top surface and if $T$ is the pressure melting point at the bottom surface and if the motion of ice within a glacier is always parallel to the bed then so long as

$$
T-T_{t} \leqslant S \tau d J D \quad . \quad . \quad . \quad . \quad .
$$

the pressure melting mechanism can operate. If $T-T_{t}>S \tau d J D$ a glacier cannot slide because not enough heat can be produced at the bottom surface to keep it at the pressure melting point. If $S$ is equal to $40 \mathrm{~m}$./year and $d$ is equal to $100 \mathrm{~m}$. the lowest value $T_{t}$ can take and still have sliding is $-6^{\circ} \mathrm{C}$. If the geothermal heat flow is taken into account $T_{t}$ may be even lower $\sim-9^{\circ} \mathrm{C}$. 
If melt water percolates down during the summer these calculations will be upset. For this situation it should be even more probable that the bottom surface will be at the melting point.

If there is appreciable vertical motion of ice within a glacier these conclusions as to the rate of heat flow through a glacier have to be modified. Robin ${ }^{9}$ has made calculations of expected temperature distributions for this complicated situation. Robin's calculations show that the temperature of the top surface must be closer to the melting point than equation (2) would allow whenever the bottom surface is at the pressure melting point. The problem of estimating the bottom temperature of a non-temperate glacier is, needless to say, difficult.

The speed of sliding of a glacier over the bed pictured in Fig. $x$ is equal to the volume of ice melted per unit time in front of a protuberance divided by the cross sectional area of the protuberance. If the heat conductivity of the bed rock is the same as that of ice (and this is approximately true) then the volume of ice melted per unit time is approximately

$$
\Delta T D L / H \rho
$$

The speed of sliding $S_{p m}$ is given by the equation

$$
S_{p m}=(\tau C D / 3 H \rho L)\left(L^{\prime 2} / L^{2}\right)
$$

The speed of sliding decreases as $L$ is increased if the ratio $L^{\prime} / L$ is held constant. In Fig. 2 (p. 37) is shown a plot of $S_{p m}$ versus $L$. The values of $S_{p m}$ were calculated assuming that $L^{\prime} / L$ is equal to four and using the values $H=80 \mathrm{cal} . / \mathrm{gm} ., D=0.005 \mathrm{cal} .{ }^{\circ} \mathrm{C}$. $\mathrm{sec} . \mathrm{cm}$., and $\tau=10^{6}$ dynes $/ \mathrm{cm} .{ }^{2}$. The value of $\tau$ which is assumed is the approximate value which Nye's analysis ${ }^{2}$ shows exists at the bottom of most glaciers*.

A more realistic model of a glacier bottom would be to assume that there are protuberances of dimension $L$ separated from each other by a distance $L^{\prime}$ and that superimposed on these protuberances there are smaller ones of dimensions $L /$ ro which are separated by a distance $L^{\prime} /$ ro and superimposed on these smaller obstacles are still smaller ones of dimensions $L / 100$ which are separated by a distance $L^{\prime} /$ roo and so on to the smallest conceivable protuberances. We now assume this model for our glacier bed.

Now suppose at a given instant in time the protuberances of the smallest order of magnitude are supporting the major portion of the shear stress exerted on the glacier bottom. By equation (3) the sliding velocity of a glacier would be greatest for these protuberances. After a small amount of sliding it is easy to see that protuberances of the next larger order of magnitude would begin to support the major portion of the shearing stress. The sliding velocity would be reduced an order of magnitude. After still more sliding larger and larger protuberances would take over the job of supporting the shear stress at the bottom until the largest obstacles are supporting the glacier. If $L^{\prime} / L$ is of the order of four, protuberances larger than $100 \mathrm{~cm}$. would limit the sliding velocity to negligible amounts. Thus we see that pressure melting by itself cannot explain glacier sliding.

\section{EfFect of Stress Concentrations}

Consider again Fig. I. Assume again that a smooth ice-rock interface cannot support a tangential stress and ignore for the moment pressure melting effects. Ice will flow around the protuberances in the manner shown in Fig. 3 (p. 37). The ice will close in behind an obstacle after flowing around it because of the hydrostatic pressure (which is at least an order of magnitude greater than the shear stress at the bottom of a glacier).

\footnotetext{
* The reason for the near constancy of $\tau$ from glacier to glacier is quite clear from Nye's analysis. Consider a glacier sliding down a bed of slope $a$ whose top surface is parallel to the glacier bed. If the sliding at the glacier bottom is neglected, then by Nye's analysis the net amount of ice passing any reference point in a unit time is proportional to $\tau^{n+2} / \sin ^{2} \alpha$ where $\tau$ is the shear stress at the bottom of the glacier. Now the net amount of ice passing by any reference point is about equal to the net amount of snow accumulating at the head of a glacier. Thus $\tau$ is proportional to the rate of accumulation of snow to a $\mathbf{I} /(n+2)$ power. Since $n$ is of the order of 4 , a millionfold change in the rate of snow accumulation would only alter the shearing stress at the glacier bottom by a factor of ten. Hence $\tau$ is essentially a constant whose value happens to be approximately $10^{6}$ dynes $/ \mathrm{cm} .2$.
} 
The compressive stress on the high stress side of an obstacle in Fig. I should be of the order of $\frac{1}{2} \tau L^{\prime 2} / L^{2}$. On the low stress side there should be a tensile stress of this magnitude. From equation (I) the creep rate near an obstacle is of the order $2^{-n} B \tau^{n}\left(L^{\prime 2} / L^{2}\right)^{n}$. To obtain a velocity of sliding from the creep rate it is necessary to know the distance over which the stress is essentially at the level $\frac{1}{2} \tau L^{\prime 2} / L^{2}$. A reasonable estimate which uses Nye's value of the stress around contracting holes ${ }^{3}$ gives the value $L$, on either side of the obstacle, for this characteristic distance. Hence the velocity of sliding $S_{s c}$ is given by the equation

$$
S_{s c}=B\left(\frac{1}{2} \tau L^{\prime 2} / L^{2}\right)^{n} L
$$

Curve 2 of Fig. 2 shows velocities of sliding for different values of $L$ assuming that $L^{\prime} / L$ is equal to 4 and using the values $\tau=10^{6}$ dynes $/ \mathrm{cm}^{2}=\mathrm{r}$ bar, $B=0.017$ bars ${ }^{-4 \cdot 2}$ years $^{-1}$, and $n=4^{*} 2$. These last two values are those found by Glen ${ }^{4}$ when the transient portions of his creep curves are subtracted from the total creep curves. Equation (4) predicts a rate of sliding which increases with increasing obstacle size. This prediction is just the opposite to that which was found for pressure melting.

Now consider as we did before what the effect of having a range of obstacle sizes will be. If, in Fig. I, the surface between the obstacles of dimension $L$ are not smooth but contain obstacles of dimensions $L / \mathrm{IO}$, this surface will be able to support a tangential stress. Since by equation (4)

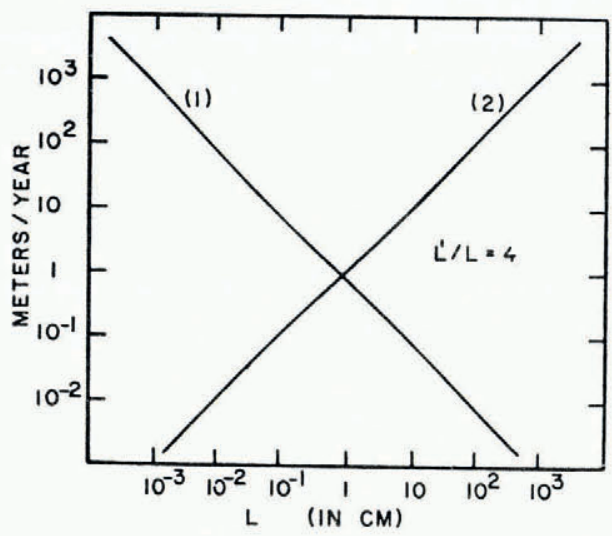

Fig. 2. Logarithm of sliding velocity versus logarithm of protuberance size. Curve $I$ : velocity due to pressure melting. Curve 2: velocity due to stress concentrations. The ratio $L^{\prime} / L$ is assumed to be equal to four
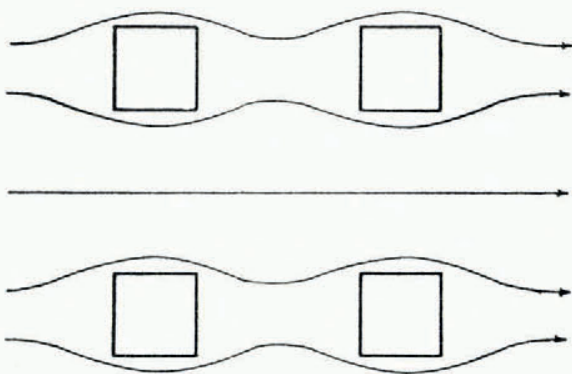

Fig. 3. Streamlines of ice flow around obstacles

the sliding velocity decreases as the protuberance size decreases the sliding velocity will be determined by obstacles of size $L /$ ro instead of those of $L$. Repeating the argument, protuberances of dimensions $L / 100, L / 1000$, etc. should determine the sliding rate. Or in other words the rate of sliding will again be negligibly small.

\section{Combined Mechanisms}

Since the speed of sliding by the pressure melting mechanism increases with decreasing obstacle size and the stress concentration mechanism gives a rate which increases with increasing obstacle size, a combination of these two mechanisms operating at the same time may give rise to appreciable sliding.

Consider Fig. 2. We consider now a glacier bed which contains a full spectrum of protuberance sizes. If the speed of sliding is controlled by obstacles whose dimensions lie to the left of the intersection of the two curves, the speed of sliding should be determined by the pressure melting 
effect since it is fastest in this region. If we repeat our old argument against using pressure melting alone, then the only obstacle size which can be used in this region is the largest, namely, that given by the intersection of the two curves.

If the sliding is controlled by obstacles which lie in the region to the right of the intersection of the two curves in Fig. 2, then the speed of sliding is controlled by the stress concentration mechanism since it is fastest in this region. Again repeating our argument against using this mechanism alone, the speed of sliding must be controlled by the smallest protuberances in this region. The size of these protuberances is again given by the intersection of the curves in Fig. 2. The obstacles of this size then control the rate of sliding.

On setting equations (3) and (4) equal to each other and solving for $L$, the following equation is obtained for the sliding velocity

$$
\text { sliding velocity }=\left(\frac{2 B C D}{3 H \rho}\right)^{\frac{1}{2}}\left(\frac{\tau}{2}\right)^{\frac{\mathrm{r}+n}{2}}\left(\frac{L^{\prime}}{L}\right)^{\mathrm{x}+n}
$$

The high power over the term $L^{\prime} / L$ is rather unfortunate since only estimates can be made of this term. A value of $L^{\prime} / L$ equal to 4 in equation (5) would give a sliding rate of one meter per year which is almost within the range estimated by $\mathrm{Nye}^{2}$ for a number of glaciers ( 4 to $79 \mathrm{~m}$./year).

It clearly would be helpful if a frequency distribution of protuberance sizes and separations could be found on several exposed glacier beds so that the sliding model proposed here may be better tested. Laboratory tests could be easily carried out to test this theory.

The author wishes to thank Dr. Peter Haasen for first arousing his curiosity in the problem of glacier flow and Dr. J. W. Glen for a number of valuable suggestions for improving the calculations. MS. received 28 March $195^{6}$

\title{
RE F E R E N CES
}

I. Nye, J. F. The flow of glaciers and ice-sheets as a problem in plasticity. Proceedings of the Royal Society, Ser: A,

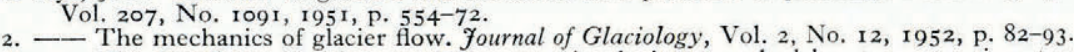

3. - The flow law of ice from measurements in glacier tunnels, laboratory experiments and the Jungfraufirn borehole experiment. Proceedings of the Royal Society, Ser. A, Vol. 219, No. II39, I953, p. 477-89.

4. Glen, J. W. The creep of polycrystalline ice. Proceedings of the Royal Society, Ser. A, Vol. 228, No. 1175, 1955,

p. 5 19-38.
5. Gerrard, J. A. F., Perutz, M. F., and Roch, A. Measurement of the velocity distribution along a vertical line through a glacier. Proceedings of the Royal Society, Ser. A, Vol. $21_{3}$, No. 1115,1952, p. 546-58.

6. McCall, J. G. The internal structure of a cirque glacier, report on the studies of englacial movements and temperatures. Fournal of Glaciology, Vol. 2, No. 12, I952, p. 122-30.

7. Ward, W. H. Studies in glacier physics on the Penny Ice Cap, Baffin Island, 1953. Part IV: The flow of Highway Glacier. Fournal of Glaciology, Vol. 2, No. r 8, 1955, p. 592-98.

8. Fermi, E. Thermodynamics. New York, Prentice-Hall, 1937, p. 68.

9. Robin, G. de Q. Ice movement and temperature distribution in glaciers and ice sheets. fournal of Glaciology, Vol. 2, No. 18 , 1955, p. 523-32.

\section{DEFORMATION OF FLOATING ICE SHEL VES}

\section{By J. Weertman}

(Naval Research Laboratory, Washington, D.C.)

\begin{abstract}
The problem of the creep deformation of floating ice shelves is considered. The problem is solved using Glen's creep law for ice and Nye's relation of steady-state creep (the analogue of the Lévy-Mises relation in plasticity theory). Good agreement is obtained between an observed creep rate at Maudheim in the Antarctic and that predicted from the results of creep tests made by Glen.

Zusammenfassung. Das Problem der Kriechdeformation einer schwimmenden Eisplatte wird mit Hilfe von Glen's Eiskriechgesetz und Nye's Gleichung für den Kriechgleichgewichtszustand gelöst (Nye's Gleichung ist der Lévy-Mises Gleichung in der Plastizitätstheorie analog.). Auf diese Weise wird die in Maudheim in Antarktika beobachtete Kriechgeschwindigkeit mit der von den Glen'schen Experimenten zu erwartenden in Einklang gebracht.
\end{abstract}

\section{INTRODUCTION}

The problem of the flow of ice in glaciers and ice caps has been treated by Nye in a series of very illuminating papers $1,2,3,4,5$. One problem that has not been analyzed by his methods is 